\title{
Initial results on the use of mechanical devices for proximal saphenous vein graft anastomoses: a clinical and angiographic evaluation
}

\author{
Resultados iniciais com a utilização da anastomose mecânica aorto-safena: uma avaliação clínica \\ e angiográfica
}

Fabio B. JATENE ${ }^{1}$; Luís Alberto O. DALLAN ${ }^{1}$; Alexandre C. HUEB ${ }^{1}$; Luiz A. LISBOA ${ }^{1}$; Rosangela MONTEIRO ${ }^{1}$; Flávio R. TAKEDA ${ }^{1}$; José Flávio G. MARIN ${ }^{1}$; Sérgio A. OLIVEIRA ${ }^{1}$

RBCCV 44205-654

\section{Abstract}

Objective: To report on our initial clinical experience of the utilization of a mechanical anastomotic device (MAD) to perform saphenous vein graft to aorta anastomosis.

Method: Between June 2002 and May 2003, 17 patients, including 13 male, with a mean age of $64.4 \pm 9.4$ years, were selected for coronary artery bypass grafting using MAD. A total of 49 anastomoses, 19 arterial and 30 vein grafts, were performed with a mean of $2.9 \pm 0.5$ anastomoses per patient. Eleven $(36.7 \%)$ vein-graft anastomoses were performed with conventional sutures and $19(63.3 \%)$ using MAD. The clinical evolution, enzymatic and electrocardiographic alterations as well as an angiographic study were analyzed in the postoperative period.

Results: Of the 17 patients, the mechanical device was used on $16(94.1 \%)$. Six $(37.5 \%)$ patients were operated on under cardiopulmonary bypass with a mean time of $102.9 \pm$ 16.9 minutes. The postoperative evolution was satisfactory in all patients. No patient presented with enzymatic, myocardial infarction or other ischemic electrocardiographic alterations in the immediate postoperative period. Early postoperative angiography was performed in $9(52.9 \%)$ patients. The anastomoses of the left internal thoracic artery to left anterior descending artery were patent in all cases. Of the 15 saphenous vein grafts studied, $11(73.3 \%)$ were performed using MAD, $9(81.8 \%)$ of which were patent. All the 4 conventionally sutured vein anastomoses were patent. No hospital deaths occurred. In the late follow-up, $88.2 \%$ of the patients were free of cardiac-related events.

Conclusions: MAD for vein graft-to-aorta anastomosis proved to be feasible, but a wider analysis of the benefits of its utilization regarding operative time, aggression to the patient, patency of the grafts and final cost are necessary.

Descriptors: Cardiovascular diseases, surgery. Myocardial revascularization, methods. Coronary disease, surgery.
Work performed in the Heart Institute of the Hospital das Clínicas, Medical School, University of São Paulo. São Paulo, SP, Brazil Presented at the 30th National Congress of Cardiac Surgery, Goiânia Brazil April 2003

1 - Heart Institute of the Hospital das Clínicas, Medical School, University of São Paulo. São Paulo, SP, Brazil

Correspondence address:

Fabio B. Jatene. Instituto do Coração

Serviço de Cirurgia Torácica.

Av. Dr. Enéas de Carvalho Aguiar, 44

$2^{\circ}$ andar, bloco II. Cerqueira César. São Paulo, SP.

CEP: 05403-900.

Phone.: (11) 3069-5248. Fax: (11) 3069-5372.

E-mail: fabiojatene@incor.usp.br
Article received on April, 2003 Article accepted on October, 2003 


\section{Resumo}

Objetivo: Relatar nossa experiência inicial com utilização do dispositivo mecânico para realização de anastomose aortasafena.

Método: Entre junho/2002 e maio/2003, 17 pacientes (pts) foram selecionados para emprego de anastomose mecânica, sendo 13 homens, com idade média de $64,4 \pm 9,4$ anos, portadores de doença arterial coronariana. Foram realizadas $2,9 \pm 0,5$ anastomoses/paciente, totalizando 49 , sendo $19 \mathrm{com}$ utilização de enxertos arteriais e 30 com veia safena. Dentre as pontes de veia safena, $11(36,7 \%)$ foram convencionais e 19 $(63,3 \%)$ utilizaram sutura mecânica (SM) aorto-safena. No período pós-operatório, foram analisados evolução clínica, alterações enzimáticas e eletrocardiográficas, bem como estudo angiográfico das anastomoses.

Resultados: Dos 17 pts, a SM foi empregada em $16(94,1 \%)$. Utilizou-se circulação extracorpórea em $6(37,5 \%)$ dos 16 pts que receberam $\mathrm{SM}$, com tempo médio de $102,9 \pm 16,9$ minutos. A evolução pós-operatória foi satisfatória em todos os pts. No

\section{INTRODUCTION}

Based on the work by FAVALORO et al. [1], the use of saphenous vein grafts spread quickly, becoming from that moment on an important therapeutic option for the treatment of coronary insufficiency. Over the years, several other grafts were incorporated into this operation.

Publications establish advantages in the utilization of arterial compared to venous grafts as a therapeutic option [2-4], but due to the limitations caused by coronary artery bypass grafting with the exclusive use of arterial grafts, the venous conduit continues to be a good option.

During the proximal anastomosis of the saphenous vein grafts and the aorta, there is a necessity to manipulate the aorta utilizing partial of total clamping. This fact predisposes patients to one of the most serious post-operative complications, embolia of arteriosclerotic fragments of the aorta [5-7].

Several studies were performed aiming at identifying the predisposing factors for the event of embolism, such as the involvement of three arteries [8], severe coronary disease [9] and principally, a prolonged period of aortic manipulation. With respect to the latter, several techniques have been suggested, such as single cross-clamping of the aorta, single proximal and distal clamping, utilization of intra-operative ultrasound of the aorta and, even, not to use clamping.

For this reason, the techniques employed in coronary artery bypass grafting have been modified over the years. Performing this operation without the use of cardiopulmonary bypass, or even the minimally invasive surgical techniques, have the intention of improving the obtained results, as pós-operatório, não foram observadas alterações isquêmicas ou IAM em nenhum paciente. $O$ estudo angiográfico das anastomoses foi realizado em $9(52,9 \%)$ pts. As anastomoses da artéria torácica interna esquerda para ramo interventricular anterior apresentavam-se pérvias em $100 \%$ dos casos. Das 15 anastomoses de veia safena estudadas, 11 $\mathbf{7 3 , 3 \%}$ ) eram de SM e $9(\mathbf{8 1 , 8 \%})$ apresentavam-se pérvias. Todas anastomoses convencionais de veia safena estavam pérvias. Não se observou óbito hospitalar. No seguimento tardio, $\mathbf{8 8 , 2 \%}$ dos pacientes apresentam-se livres de eventos cardiovasculares.

Conclusões: A SM mostrou-se factível, mas é necessária uma análise mais ampla dos benefícios de sua utilização em relação ao tempo operatório, agressão ao paciente, perviabilidade do enxerto e custo final.

Descritores: Doenças cardiovasculares, cirurgia. Revascularização miocárdica, métodos. Coronariopatia, cirurgia.

well as reducing the operative risks and their complications [10]. State-of-the-art technology has been incorporated into the routine of cardiac surgeons, attempting to provide better conditions of less invasive procedures. Among these methods, mechanical sutures joining vessels is becoming more interesting in the attempt of making anastomosis more efficient, safe and rapid [11-13].

Thus, the utilization of the aorta-saphenous mechanical suture technique has become an option for reducing the manipulation of the aorta, presenting with good preliminary results in studies performed at different centers [14-16].

This work aims at reporting our initial experience with the utilization of the mechanical device to perform aortasaphenous anastomosis.

\section{METHOD}

After approval of the Scientific Ethics Committee of the Heart Institution, 17 patients during the period from June 2002 to May 2003 were enrolled in a prospective study employing mechanical anastomosis. Thirteen $(76.5 \%)$ of the patients were male and the ages ranged from 48 to 79 years (mean of $64.4 \pm 9.4$ years).

All the patients suffered from chronic coronary disease with comorbidities including systemic arterial hypertension (76.5\%), previous infarction (47.1\%), diabetes mellitus type II (41.2\%), dyslipidemia (41.2\%), anginal symptoms (29.4\%) and previous angioplasty $(5.9 \%)$.

In $13(76.5 \%)$ patients three arteries were involved, in three $(17.6 \%)$ patients multiple arteries and in one $(5.9 \%)$ patient a single artery. 
Exclusion criteria were reoperations, emergency operations, an ejection fraction $\leq 35 \%$, previous neurologic alterations and age greater than 80 years.

Cardiopulmonary bypass was utilized in six (37.5\%) of the 15 patients in which the mechanical sutures were employed with times ranging from 80 to 128 minutes and a mean of $102.9 \pm 16.9$ minutes. Aortic clamping times varied from 39 to 82 minutes (mean of $53.4 \pm 14.6$ minutes).

On average $2.9 \pm 0.5$ anastomosis were performed on each patient, in a total of 49 anastomosis, with 17 using the left internal thoracic artery, one using the right internal thoracic artery, one the left radial artery and 30 utilizing the saphenous vein. Among the saphenous vein grafts, 11 (36.7\%) were performed in the conventional manner and 19 $(63.3 \%)$ utilizing mechanical aorta-saphenous sutures (St. Jude Medical Symmetry Aortic Connector).

The mechanical sutures were preferentially used for coronary branches of the circumflex artery and the right coronary artery, with the anterior interventricular artery treated utilizing the left internal thoracic artery. One or two mechanical sutures were employed per patient, depending on the evaluation during the operation.

The suturing device is composed of an aortic connector (pre-installed on the liberation tubes), cable, protection cone, aortotomy, vein transference sheath and vein perforator.

Assemblage of the connector followed the instructions of use established by the manufacturer and several components of the device are illustrated in Figure 1. Basically, the saphenous vein was externally adjusted on a rod and internally in a plastic cylinder, fixed with hooks at its ends (Figure 2).

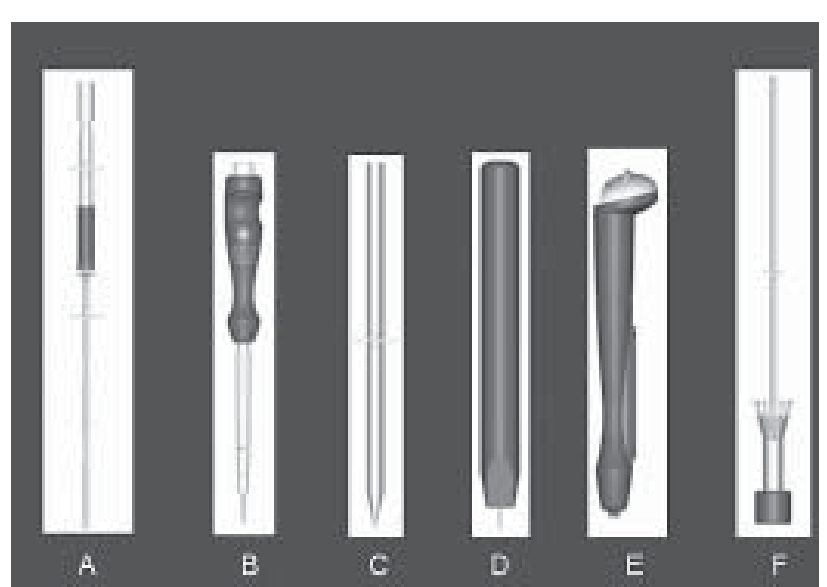

Fig. 1 - Design of the different components of the mechanical suture device. A - aortic connector loaded on the liberation system; $\mathrm{B}$ - aortotomy; C - graft transference sheath; D - perforator; E cable; $\mathrm{F}$ - protection cone

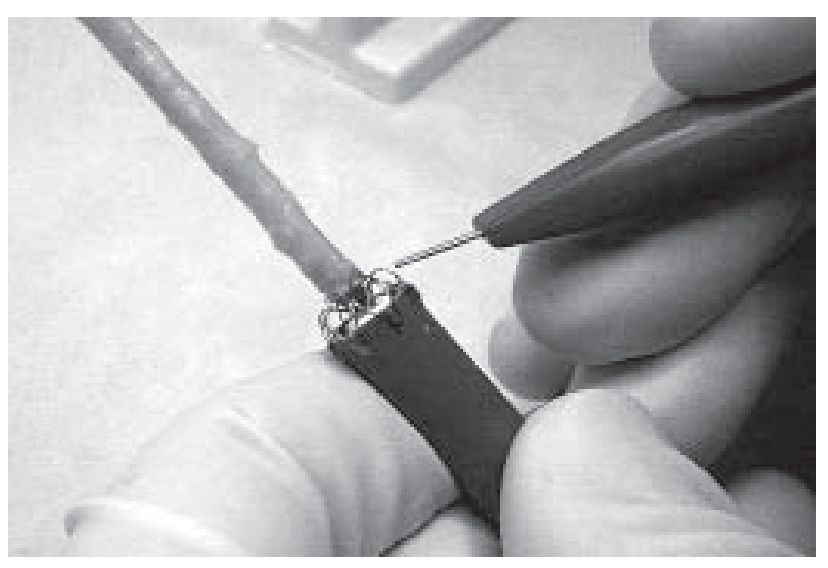

Fig. 2 - Details of the assemblage of the saphenous vein performed on a bench

Once prepared, the assemblage of the vein mounted on the device was immersed in saline solution, whilst the aorta was prepared. The next step was to prepare the site of the anastomosis, using the aortotomy to make an orifice in the aortic wall (Figure 3).

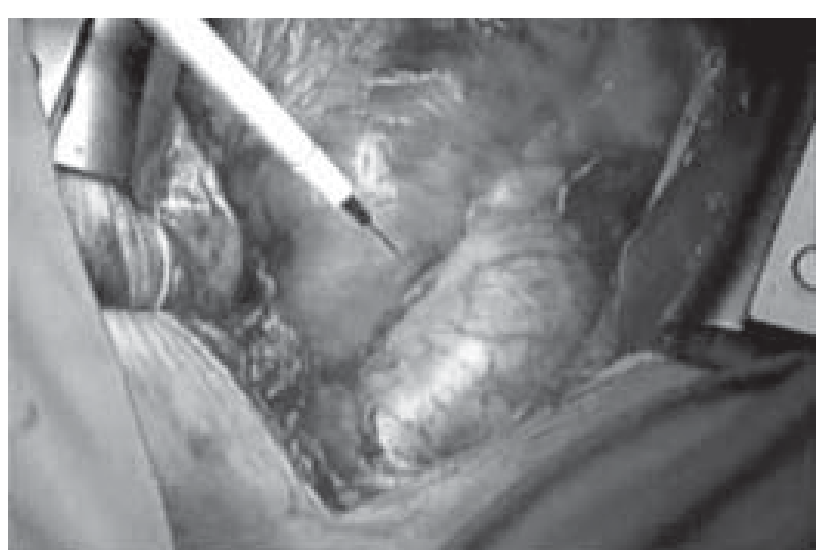

Fig. 3 - Intra-operative photograph exhibiting details of the approach of the aortotomy to the aorta.

After removing the aortotomy, a finger was placed over the aortic orifice to prevent bleeding. The end of the assemblage, with the staples fixed to the vein, was inserted into the orifice and the application was performed by pressing a button at the other end of the device. Following this, the assemblage was gently withdrawn, leaving the vein sutured to the aorta (Figure 4). Finally, an evaluation of the anastomosis was performed in relation to the seal.

It is necessary to emphasize that the proximal anastomoses were performed before the distal anastomoses when utilizing the mechanical sutures. When there was necessity of cross-clamping of the aorta to perform the conventional proximal anastomosis, this was always performed before employing the mechanical suturing. 


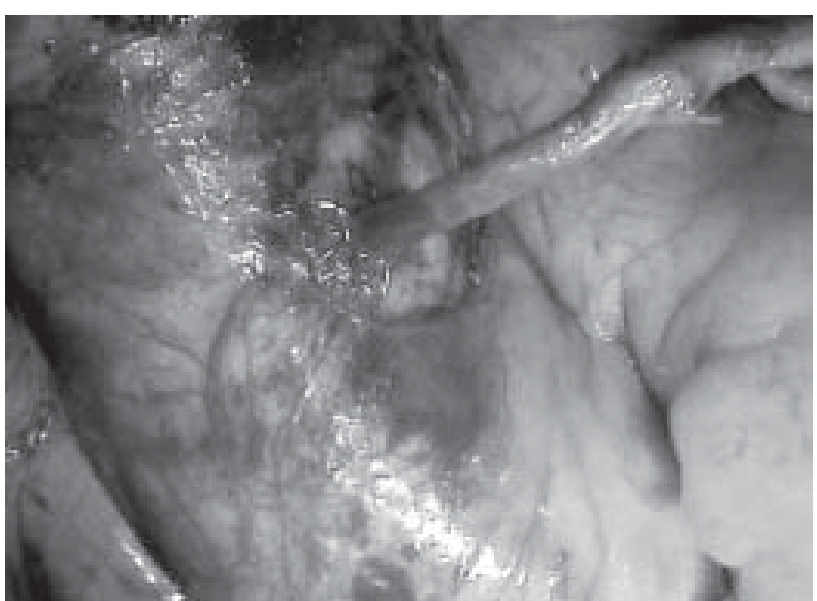

Fig. 4 - Final view of the aorto-saphenous anastomosis with the mechanical device

In the immediate post-operative period, the clinical evolution, particularly the neurologic and cardiological alterations (enzymatic and electrocardiographic) were analyzed. Additionally, an angiographic study was performed of the anastomoses within a period which ranged from 6 to 13 days ( $8.1 \pm 2.2$ days) after the operation.

In the late post-operative period, a clinical examination and a new catheterism was performed in two patients.

\section{RESULTS}

Of the 17 patients selected for the study, mechanical sutures were employed in $16(94.1 \%)$, as in one $(5.9 \%)$ case its use was not possible due to the unfavorable anatomy of the great vessels which could lead to kinking of the graft. Among the 16 patients who received the mechanical sutures, there was a necessity to revert to conventional suturing in one $(5.9 \%)$ case after application due to focused peri-sutural leakage, that after inspection revealed a failure in the setting up of the vein on the device (Figure 5).

The connector was employed in aorto-saphenous anastomoses for the marginal branches of the circumflex artery, posterior interventricular branch, diagonal, diagonalis and right coronary artery (Table 1).

The post-operative evolution was satisfactory in all the patients, although some adverse events occurred - arterial fibrillation (5.9\%), acute respiratory insufficiency $(5,9 \%)$ and infection of the thoracic wound $(11.8 \%)$ - which did not influence the final results. The enzymatic and electrocardiographic studies performed in the immediate post-operative period did not evidence ischemic alterations or acute myocardial infarction in any of the patients.

Angiographic studies of the anastomoses were performed in nine $(52.9 \%)$ of the patients. Despite of all the patients being clear about the necessity of performing

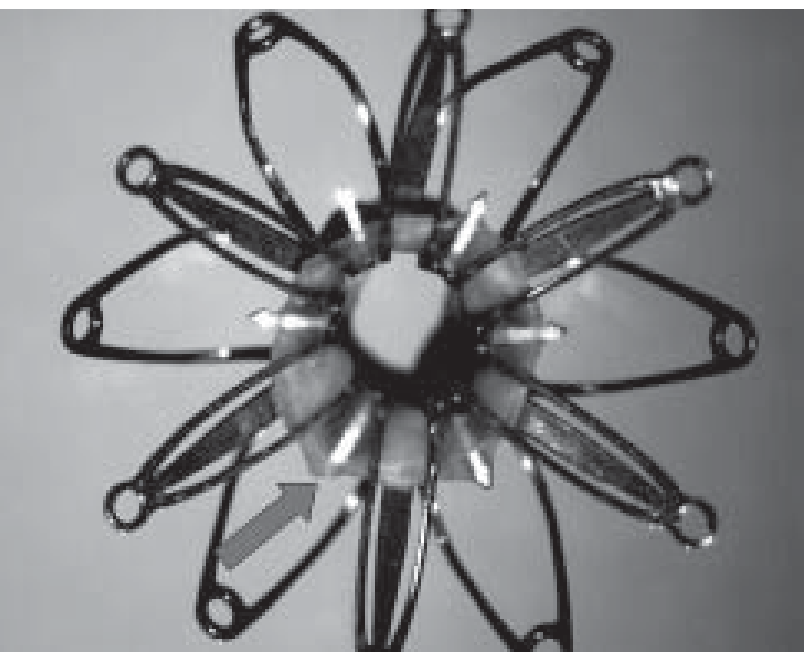

Fig 5 - Photograph of the device that was implanted and immediately removed after the anastomosis presented with bleeding. N.B. the arrow shows that there was a mistake in setting up the device, where one pin did not pass through the vein

Table 1. Location of the anastomoses - the bold represents the anastomoses performed using mechanical sutures

\begin{tabular}{|c|c|c|c|c|}
\hline \multirow[t]{2}{*}{ PATIENT } & \multicolumn{3}{|c|}{ GRAFT } & \multirow[t]{2}{*}{ CAT IPO } \\
\hline & LITA & PS & PS & \\
\hline 1 & AIB & LMg & - & yes \\
\hline 2 & AIB & LMg & RC & yes \\
\hline 3 & AIB & LMg & PIB & yes \\
\hline 4 & AIB & $\mathrm{LMg}$ & PIB & yes \\
\hline 5 & AIB & Dgls & PIB & no \\
\hline 6 & AIB & $\mathrm{LMg}$ & PIB & no \\
\hline 7 & AIB & LMg & $\mathrm{RC}$ & yes \\
\hline 8 & AIB & Dg & $\mathrm{RC}$ & no \\
\hline 9 & AIB & $\mathrm{LMg}$ & RC & no \\
\hline 10 & AIB & Dgls * & PIB & no \\
\hline 11 & AIB & PIB & 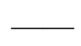 & yes \\
\hline 12 & AIB & LMg & $\mathrm{RC}$ & yes \\
\hline $13 * *$ & AIB & Dg & $\mathrm{LMg}$ & no \\
\hline 14 & AIB & Dg & $\mathrm{LMg}$ & yes \\
\hline 15 & AIB & Dg & LMg & no \\
\hline 16 & AIB & LMg & 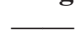 & yes \\
\hline $17 * * *$ & AIB & PIB & 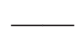 & no \\
\hline
\end{tabular}

Legend: LITA - left internal thoracic artery; SG - saphenous vein graft; AIB - anterior interventricular branch; $\mathrm{LMg}$ - left marginal branch; Dg - diagonal branch; Dgls - diagonalis branch; RC - right coronary artery; PIB - posterior interventricular branch. CAT IPO - catheterism performed in the immediate post-operative period

* reversal to conventional suture; ** unfavorable anatomy;

$* * *$ additional grafts employed: right internal thoracic artery to $\mathrm{LMg}$ and left radial artery to $\mathrm{Dg}$. 
angiographic studies in the post-operative period for them to be included in the protocol of the study, six (35.3\%) refused to do the examination after the operation, even having signed the written consent forms. Additionally, two (11.8\%) of the patients did not do the angiographic study due to complications at the surgical wound.

In relation to the immediate angiographic studies, the anastomoses of the left internal thoracic arteries to the anterior interventricular branch presented patency in nine $(100 \%)$ of the cases. Of the 15 saphenous vein grafts, 11 $(73.3 \%)$ were mechanical sutures nine $(81.8 \%)$ of which were patent (Figure 6)

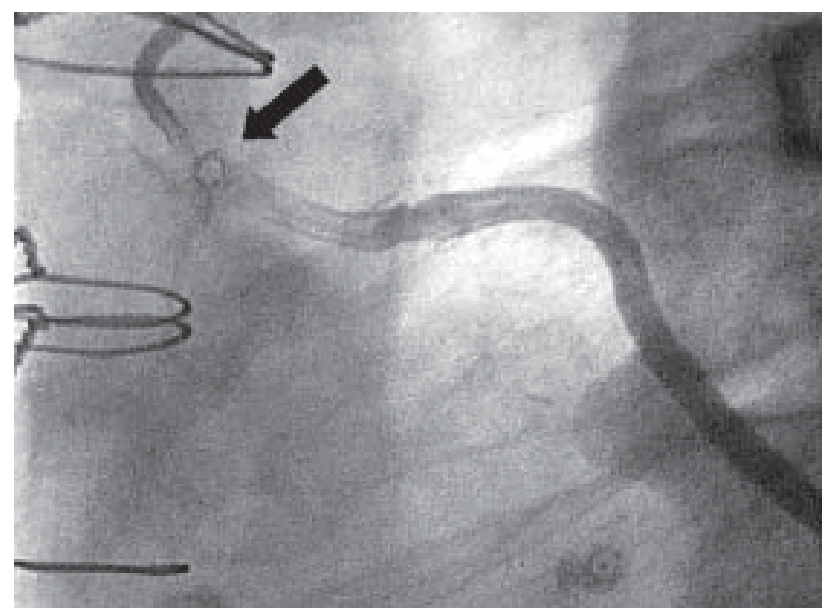

Fig. 6 - Post-operative angiographic study of a patient submitted to an anastomosis saphenous graft to the diagonal branch utilizing a mechanical suture. N.B. observe the metallic device.

All of the four conventional saphenous vein grafts were patent.

No hospital mortality was seen. Release from hospital occurred between 5 and 27 post-operative days with a mean of $11.4 \pm 5.2$ days.

Two patients presented with anginal episodes, one (patient $\mathrm{N}^{\circ} 2$-Table 1) at 13 months and the other (patient $\mathrm{N}^{\circ} 5$ ) at 9 months of the operation. At this point a catheterism was performed in both patients revealing occlusion of the graft of the left marginal and injury to the saphenous graft for the right coronary in patient $\mathrm{N}^{\circ} 2$ (Figure 7) and both grafts were occluded in patient $\mathrm{N}^{0} 5$. In both patients, the anastomoses of the left internal thoracic artery to the anterior interventricular branch were patent.

In the long-term follow up, which ranged from 3 to 14 months $(11.1 \pm 2.7$ months $)$, the other patients $(88.2 \%)$ presented free of anginal symptoms or cardiovascular events.

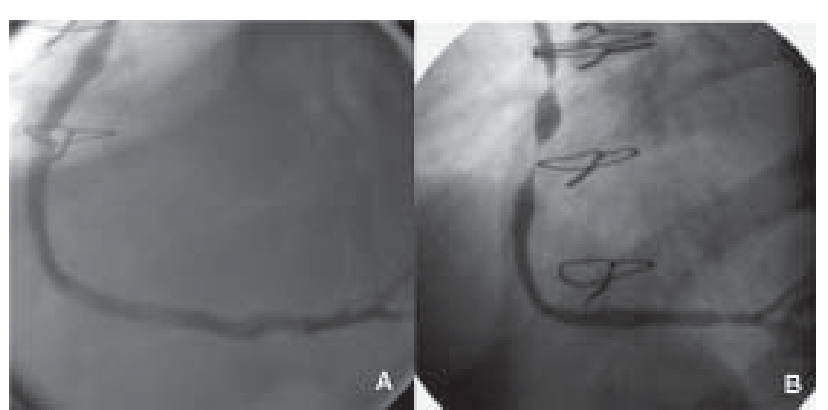

Fig. 7 - Post-operative angiographic study of a patient submitted to an anastomosis saphenous graft to the right coronary artery utilizing a mechanical suture. A. Catheterism performed in the immediate post-operative period demonstrating a patent saphenous vein graft. B. Catheterism performed 13 months after the operation, revealing the saphenous vein graft with serious injuries

\section{COMMENTS}

Several modifications in vascular suturing techniques have been proposed over the years [15], such as the use of vascular staples [17], tissue adhesives [18], clips [19] and the utilization of laser [20]. All, with the intention of facilitating the surgical procedure to be performed, as well as to reduce the time spent.

Currently, the conventional manual suture is still the gold standard method, because it is rapid, simple, cheap and effective to perform the proximal anastomoses [21]. However, the utilization of a mechanical suturing device has the advantage of minimizing the handling of the aorta, as it dispenses with total or partial aortic clamping, in patients with chronic arterial disease. This is especially important in aortas affected by atheroma plaques, thereby reducing the risks of embolization in the post-operative period [15,22]. Other possible advantages are the reduction of time spent in performing the anastomoses and a reduction in the "human dependent' factor, that is, the mechanical suture provides a standardization of the anastomosis, independent of the experience and the ability of the surgeon. There is also the possibility of the utilization of the mechanical suture with the objective of facilitating the anastomosis in minimally invasive operations, including by robot.

Among the disadvantages of the mechanical sutures, the high cost when compared to conventional sutures should be considered and the absence of a longer followup period and, thus, their reliability. Additionally, until now, devices that can only be employed with saphenous vein grafts and on proximal anastomoses are available commercially.

Another aspect that is not a disadvantage, but should be considered is that many surgeons are not familiar with performing proximal anastomoses before the distal 
anastomoses, a fact that deserves special care in estimating the length of the graft. It is necessary to emphasize the need of maintaining an angle of about 90 degrees between the aorta and the saphenous vein graft, which is not common for the majority of surgeons, who use a lesser angle between the vessels. Thus, it is necessary to choose an appropriate site on the aorta, so that the saphenous vein graft maintains the recommended angle. The difficulty in positioning of the graft and the presence of kinking due to an incorrect graft size were cited by some authors as probable reasons for occlusion and stenosis of grafts observed in their studies $[14,15,22]$. We did not detect problems of kinking or bending of the saphenous vein graft, which could potentially obstruct the blood flow or even make it difficult, although we took care to choose the best site for the anastomosis to avoid these problems.

In our study, we also experienced some difficulties already reported in the literature, such as the impossibility of implantation of the mechanical suture due to unfavorable anatomy ( 1 case $-5.9 \%)$ and problems with bleeding in the inter-operative period due to leaking in the region of the anastomosis ( 1 case $-5.9 \%$ ). In the latter case, we removed the suture and used a conventional manual suture as indicated by the manufacturer who counter-indicates the use of additional sutures. The same conduct was used by ECKSTEIN et al. [15], as additional sutures can lead to distortions of the geometry of the anastomosis with potential leaking in another region of the anastomosis.

There is a published report of a patient who on the day following the operation suffered a sudden cardiorespiratory arrest and he underwent reoperation. After removal of a hematoma that covered the aorta, the surgeons saw severe bleeding with the device found at around $2 \mathrm{~cm}$ from the aortotomy and, despite their attempt to perform a new suture and installation of an intra-aortic balloon, the patient did not survive [23].

Another aspect to be considered is the necessity of the use of antiplatelet and anticoagulant agents, because of the amount of metallic material exposed to the circulation. In Figure 8, it is possible to see details of the device, after its application, in the interior of pigs' aortas. We did not use these drugs in our patients, although several works have questioned this necessity [24].

The results of our study are similar to those found in other centers, with patency varying around 80 to $95 \%$. ANTONA et al. [22] observed $94.7 \%$ of patency in the catheterism performed previously to hospital release, in a study which included 36 patients. A patency rate of $90 \%$ was evidenced by WIKLUND et al. [14] in a restudy of 10 patients. MACK et al. [25] reported $86.6 \%$ of graft patency confirmed by angiographic studies performed on 20 patients of 67 in which the mechanical suture was employed at between 6 and 9 months after the operation.
Nevertheless, this procedure is new, with an extremely short follow-up time of patients, even when considering the preliminary works.

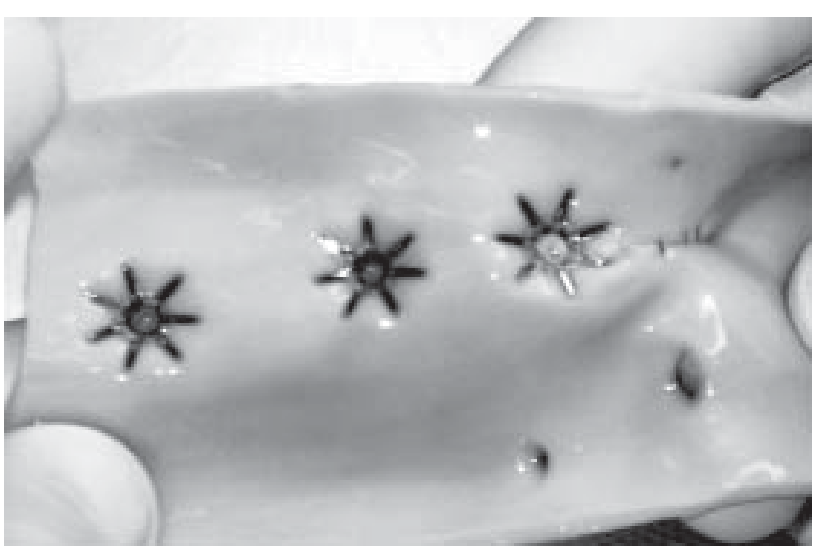

Fig. 8 - Internal view of the pig's aorta where several mechanical suture devices can be seen

The utilization of mechanical sutures and new technologies of suturing has been a great recent advance. The evolution has been very fast and second and third generation devices have emerged, attempting at achieving greater facility of the operation, better results and lower costs. For sure, the near future will bring many novelties in this field of heart surgery.

\section{CONCLUSION}

The mechanical suture proved to be feasible, with a good clinical evolution of the patients, without post-operative complications attributed to the method. However, the number of mechanical anastomosis performed is still small and the time of evolution short. Thus, further analysis of the benefits of its utilization in relation to operative time, aggression to the patient, patency of the graft and final cost are necessary.

\section{BIBLIOGRAPHIC REFERENCES}

1. Favarolo RG. Saphenous vein graft in the surgical treatment of coronary artery disease: operative technique. J Thorac Cardiovasc Surg 1969; 58:178-85.

2. Mack MJ, Osborne JA, Shennib H. Arterial graft patency in coronary artery bypass grafting: what do we really know? Ann Thorac Surg 1998; 66:1055-9. 
3. Loop FD, Lytle BW, Cosgrove DM, Stewart RW, Goormastic $\mathrm{M}$, Williams GW et al. Influence of the internal-mammaryartery graft on 10-year survival and other cardiac events. N Engl J Med 1986; 314:1-6.

4. Okies JE, Page US, Bigelow JC, Krause AH, Salomon NW. The left internal mammary artery: the graft of choice. Circulation 1984; 70:213-21.

5. Barbut D, Caplan LR. Brain complications of cardiac surgery. Curr Probl Cardiol 1997; 22:449-80.

6. van Dijk D, Keizer AM, Diephuis JC, Durand C, Vos LJ, Hijman R. Neurocognitive dysfunction after coronary artery bypass surgery: a systematic review. J Thorac Cardiovasc Surg 2000; 120:632-9.

7. Blauth CI. Macroemboli and microemboli during cardiopulmonary bypass. Ann Thorac Surg 1995; 59:1300-3.

8. Rao V, Christakis GT, Weisel RD, Ivanov J, Peniston CM, Ikonomidis JS et al. Risk factors for stroke following coronary bypass surgery. J Card Surg 1995; 10:468-74.

9. Sabik JF, Lytle BW, McCarthy PM, Cosgrove DM. Axillary artery: an alternative site of arterial cannulation for patients with extensive aortic and peripheral vascular disease. $J$ Thorac Cardiovasc Surg 1995; 109:885-91.

10. D'Ancona G, Karamanoukian HL, Ricci M, Schmid S, Bergsland J, Salerno TA. Graft revision after transit time flow measurement in off-pump coronary artery bypass grafting. Eur J Cardiothoracic Surg 2000; 17:287-93.

11. Maisano F, Franze V, De Bonis M, Alfieri O. Off-pump coronary artery surgery with the use of anastomotic devices: an additional tool for the challenging patient. Heart Surg Forum $2002 ; 5: 25-7$

12. Eckstein FS, Bonilla LF, Englberger L, Immer FF, Berg TA, Schmidli J et al. The St. Jude Medical symmetry aortic connector system for proximal vein graft anastomoses in coronary artery bypass grafting. J. Thorac Cardiovasc Surg 2002; 123:777- 82.

13. Eckstein FS, Bonilla LF, Englberger L, Eberli F, Windecker S, Berg TA et al. First clinical results with a new mechanical connector for distal coronary artery anastomoses in CABG. Circulation 2002; 106(suppl I):I1-4.

14. Wiklund L, Bugge M, Berglin E. Angiographic results after the use of a sutureless aortic connector for proximal vein graft anastomoses. Ann Thorac Surg 2002; 73:1993-4.
15. Eckstein FS, Bonilla LF, Englberger L, Stauffer E, Berg TA, Schmidli J et al. Minimizing aortic manipulation during OPCAB using the symmetry aortic connector system for proximal vein graft anastomoses. Ann Thorac Surg 2001; 72:S995-8.

16. Yau TM. Defining the role of anastomotic devices in coronary bypass surgery. J Thorac Cardiovasc Surg 2003; 125:27-9.

17. Chavanon O, Perrault LP, Menasche P. Favorable aspect of stapled anastomosis: an endothelial function study. Ann Thorac Surg 1999; 68:1443-4.

18. Gundry SR, Black K, Izutani H. Sutureless coronary artery bypass with biologic glued anastomoses: preliminary in vivo and in vitro results. J Thorac Cardiovasc Surg 2000; 120:473-7.

19. Nataf P, Hinchliffe P, Manzo S, Simpson J, Kirsch WM, Zhu YH et al. Facilitated vascular anastomoses: the one-shot device. Ann Thorac Surg 1998; 66:1041-4.

20. Bass LS, Treat MR, Dzakonski C, Trokel SL. Sutureless microvascular anastomosis using the THC: YAG laser: a preliminary report. Microsurgery 1989; 10:189-93.

21. Tozzi P, Corno AF, von Segesser LK. Sutureless coronary anastomoses: revival of old concepts. Eur J Cardiothorac Surg $2002 ; 22: 565-70$.

22. Antona C, Scrofani R, Lemma M, Vanelli P, Mangini A, Danna $P$ et al. Assessment of an aortosaphenous vein graft anastomotic device in coronary surgery: clinical experience and early angiographic results. Ann Thorac Surg 2002; 74: 2101-5.

23. Bernstein RV. This is a report of a lethal complication following application of this St. Jude aortic connector. In: 9th Annual Cardiothoracic Techniques \& Technologies Meeting; 2003; Miami Beach. Proceedings. p. 50.

24. Donsky AS, Schussler JM, Donsky MS, Roberts WC, Hamman BL. Thrombotic occlusion of the aortic ostia of saphenous venous grafts early after coronary artery bypass grafting by using the Symmetry aortic connector system. J. Thorac Cardiovasc Surg 2002; 124: 397-9.

25. Mack MJ, Emery RW, Ley LR, Cole PA, Leonard A, Edgerton JR et al. Initial experience with proximal anastomoses performed with a mechanical connector. Ann Thorac Surg 2003; 75:1866-71. 